\title{
A Medicina Geral e Familiar e a Saúde Mental Infantil: um encontro necessário
}

Cristina Ribeiro, * Cristina Marques**

A Medicina Geral e Familiar é normalmente o primeiro ponto de contacto médico com o sistema de saúde, proporcionando um acesso aberto e ilimitado aos seus utentes e lidando com todos os problemas de saúde, independentemente da idade, sexo ou qualquer outra característica da pessoa em questão. ${ }^{1}$

O médico de família ocupa nos Cuidados de Saúde Primários um lugar chave em qualquer sistema de saúde, o que lhe proporciona um conhecimento único dos problemas de saúde dos indivíduos, das famílias e das populações, nomeadamente da população infantil, que acompanha a partir da gestação e durante o crescimento e desenvolvimento desde o primeiro ano de vida. ${ }^{2}$

O médico de família deve utilizar ainda de forma eficiente os recursos de saúde, através da coordenação de cuidados, do trabalho com outros profissionais no contexto dos cuidados de saúde primários e da gestão da interface com outras especialidades, ${ }^{3}$ nomeadamente no âmbito da saúde mental infantil.

Presentemente estima-se que 10 a $20 \%$ das crianças tenha um ou mais problemas de saúde mental ${ }^{4}$ e que destas apenas uma pequena percentagem receba tratamento especializado. ${ }^{5}$

Infelizmente, mesmo em países com mais recursos que Portugal, os serviços especializados de saúde mental para crianças e adolescentes não são suficientes para dar uma resposta adequada e atempada perante um problema desta dimensão.

Melhorar a articulação e a parceria entre os serviços especializados e os Cuidados de Saúde Primários parece-nos, pois, imprescindível, diríamos mesmo urgen-

*Médica de Família. Docente da Faculdade de Medicina de Lisboa. Assessora para os Assuntos do Álcool do IDT.IP

**Psiquiatra da Infância e da Adolescência. Área de Pedopsiquiatria do Hospital Dona Estefânia Centro Hospitalar de Lisboa Central. Assessora da Coordenação Nacional para a Saúde Mental. te, para um trabalho integrado, mais coeso e eficiente, no atendimento destas situações.

Nos últimos tempos tem crescido o número de colegas que nos contactam, pedindo algum tipo de formação em saúde mental infantil e juvenil.

Os artigos deste Dossier abordam um conjunto de temas que pensamos ser abrangente e tocar áreas em que é frequentemente pedida a intervenção do Médico de Família. No artigo "A Saúde Mental Infantil e Juvenil nos Cuidados de Saúde Primários-Avaliação e Referenciação» são apresentados parâmetros para a avaliação diagnóstica da criança/adolescente e da família, indicadores para a distinção entre normal e patológico e sinais de alerta para referenciação dos casos. Nos temas «As Perturbações Emocionais - Ansiedade e Depressão na Criança e no Adolescente», «Perturbações do Comportamento e P.H.D.A.: Diagnóstico e Intervenção nos Cuidados de Saúde Primários»e «Problemas de Sono em Idade Pediátrica» são abordados aspectos inerentes ao manejo destas problemáticas pelo Médico de Família. É dada particular atenção aos factores de risco, diagnóstico, classificação, estratégias de intervenção e prognóstico. Relativamente ao artigo "A Saúde Mental na gravidez e primeira infância» verifica-se que a gravidez e os primeiros dois anos de vida da criança correspondem a momentos chave em que vários factores de risco se podem conjugar e comprometer a capacidade parental e o desenvolvimento da criança com repercussões ao longo do seu ciclo de vida.

Todos estes temas são de extrema importância em termos de Saúde Mental Infantil e daí a pertinência de os incluir num Dossier que pretende auxiliar todos os profissionais de CSP a serem mais competentes na resolução de situações relacionadas com esta matéria.

Num trabalho de investigação realizado em 2004, com o objectivo de avaliar as necessidades de formação dos profissionais dos Cuidados de Saúde Primá- 
rios, constatámos que numa população de 168 inquiridos, $88,8 \%$ considerava de grande importância a existência de um manual de recomendações clínicas em saúde mental da criança e do adolescente para uso nos Cuidados Saúde de Saúde Primários. ${ }^{6}$

É por isso com imensa satisfação que informamos que no passado dia 10 de Outubro, Dia Mundial da Saúde Mental, a Coordenação Nacional para a Saúde Mental - Alto Comissariado da Saúde lançou um pequeno manual, intitulado «Recomendações para a Prática Clínica da Saúde Mental Infantil e Juvenil nos Cuidados de Saúde Primários».

Esta publicação pode também ser consultada a partir do sítio na Internet do Alto Comissariado da Saúde: http://www.acs.min-saude.pt/pt/saudemental.

Esperamos que a informação contida no manual, a par com os artigos deste Dossier, correspondam, pelo menos parcialmente, às expectativas dos colegas ao nível da formação e possam dar um contributo para lançar novas iniciativas neste âmbito.

De salientar ainda no Dia Mundial da Saúde Mental, a publicação do livro da OMS-WONCA sobre a «Integração da Saúde Mental nos Cuidados de Saúde Primários. Uma Perspectiva Global» $\aleph^{7}$ em que sublinha a importância das pessoas serem tratadas de uma forma holística abordando tanto as necessidades físicas com as de saúde mental. O livro salienta ainda a forma como a organização dos sistemas de saúde e a articulação entre diferentes níveis cuidados podem contribuir com exemplos de boas práticas em vários pontos do Mundo.

Um médico de família com uma prática clínica ajustada às necessidades da população que serve, integrado numa equipa de saúde alargada, coesa e com formação adequada, tem um maior potencial de detectar os problemas nomeadamente na área da saúde mental infantil. Desta forma poderá responder de modo agilizado aos contextos clínicos que se lhe deparam, sendo essencial todo o investimento interdisciplinar que facilite esta abordagem.

\section{REFERÊNCIAS BIBLIOGRÁFICAS}

1. World Organization of Family Doctors (WONCA).A Definição Europeia de Medicina Geral e Familiar(Clínica Geral/ Medicina Familiar). Lisboa:WONCA EUROPA / APMCG 2002.

2. Heyrman J, ed. EURACT Educational Agenda. European Academy of Teachers in General Practice. EURACT. Leuven: 2005.

3. Jordão JG.A Medicina Geral e Familiar - Caracterização da prática e sua influência no ensino pré-graduado. (Tese de Doutoramento). Lisboa, 1995:283-8.

4. Relatório Mundial da Saúde 2001. Saúde Mental: Nova Compreensão, Nova Esperança. Ed. Ministério da Saúde, 2001.

5. Verhulst FC. Epidemiology as a Basis for the Conception and Planning of Services. In: Remschmidt H, Belfer ML, Goodyear I, Eds. Facilitating Pathways: care, treatment and prevention in child and adolescent mental health. Berlin: Springer-Verlag, 2004.

6. Marques C, Goldschmidt T, Cepêda T. Working with Primary Care. Poster apresentado no 16th World Congress of the International Association for Child and Adolescent Psychiatry and Allied Professions (IACAPAP). Berlim, Agosto de 2004. Não publicado.

7. OMS e WONCA "Integração da Saúde Mental nos Cuidados de Saúde Primários. Uma Perspectiva Global" Alto Comissariado da Saúde Out 2009 